\title{
THE STRUCTURE OF THE MATING PLUG \\ IN THE CHECKERSPOT BUTTERFLY, EUPHYDRYAS CHALCEDONA
}

\author{
By Ronald L. Rutowski, Janis L. Dickinson ${ }^{1}$, \\ AND BARBARA TERKANIAN \\ Department of Zoology, Arizona State University, \\ Tempe, AZ 85287-1501 USA
}

\section{INTRODUCTION}

During copulation, male butterflies form a package of sperm and accessory gland secretions in the bursa copulatrix of the female. In some species, males also leave material that covers to varying degrees the female's external genitalia, especially the copulatory opening or ostium bursae. This external material is known as the mating plug or sphragis and its size varies between species. In many butterflies the male produces no mating plug while in some members of the genus Parnassius and other papilionids the male produces a quantity of material that covers a large part of the ventral abdominal surface of the female (Ehrlich and Ehrlich, 1978; Drummond, 1984).

The most common functional hypothesis for the mating plug is that it impedes attempts by males to couple with mated females. As such an impediment it represents an effort by a female's last mate to protect his genetic and material investment. Last male sperm precedence appears to be the rule in butterflies (Drummond, 1984). This paper is an adjunct to an experimental study (Dickinson and Rutowski, 1989) of the function of the mating plug in the chalcedon checkerspot, Euphydryas chalcedona. Here we provide details of the structure of the mating plug and describe the persistence of the mating plugs of females held in isolation from males.

\section{Materials AND Methods}

These observations were made on individuals from a population of E. chalcedona found near Sycamore Creek in central Arizona

1Present address: Hastings Natural History Reservation, Star route Box 80, Carmel Valley, California 93924 USA

Manuscript received by the editor June 20, 1989. 
(Rutowski and Gilchrist, 1987). Virgin females were reared from larvae collected in the field and fed in the laboratory on the local hostplant, Penstemon microphyllum. Mating females were either collected in the field or obtained by mating virgin females in the field with free-flying males.

The size of a mating plug was assessed by measuring to the nearest $0.1 \mathrm{~mm}$ its greatest dimensions on the longitudinal and transverse axes, respectively. These dimensions were taken as the sides of a rectangle whose area was used as a rough estimate of the area of the genitalia covered by the mating plug.

Females were dissected to determine the number and size of spermatophores they carried. The size of the spermatophore was estimated by measuring its smallest and largest dimensions to the nearest $0.1 \mathrm{~mm}$. The midpoint between these values was taken as the diameter of a sphere whose calculated volume was used as an estimate of spermatophore volume.

For examination with the scanning electron microscope, female genitalia were mounted on a peg with a combination of Dag and Spot O' Glue (TM). The specimens were then coated in a DC sputterer for $3 \mathrm{~min}$ and examined at relatively low accelerating voltages ( $20 \mathrm{KeV}$ or less) to minimize charging effects. They were examined and photographed using an AMR-1000A scanning electron microscope.

Female age was assessed by characterization of wing wear. Each field-caught female was assigned to one of three wing wear conditions: fresh (little or no visible wing tattering or scale loss), worn (some scale loss, one or two wings torn or tattered), or very worn (substantial scale loss and tattering on all wings).

\section{RESULTS \\ Description of female genitalia}

The external genitalia of a virgin $E$. chalcedona female are shown in Figure 1 (left). The ostium bursae or copulatory opening is on the ventral midline and in the middle of a transverse groove that is anterior to two large lobes that are covered with cream-colored scales. These lobes are anterior to the ovipore and anus, and are separated by a shallow, longitudinal groove that extends along the ventral midline posteriorly from the copulatory opening toward the area of the anus and ovipore. 

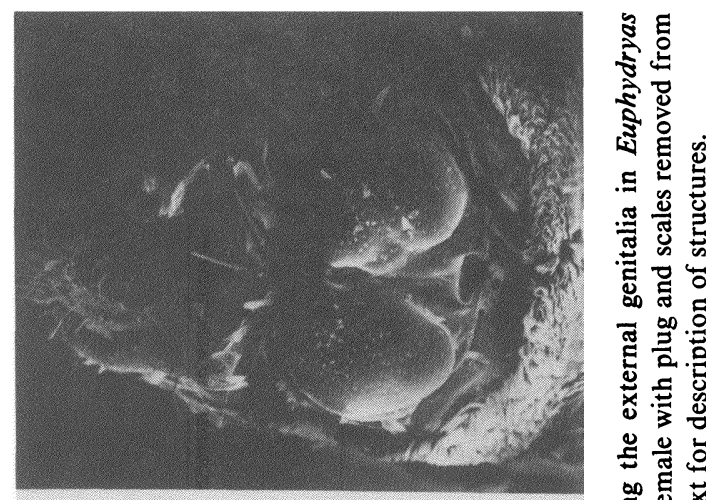

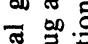

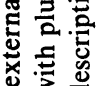
उ.

로 훈

我芯

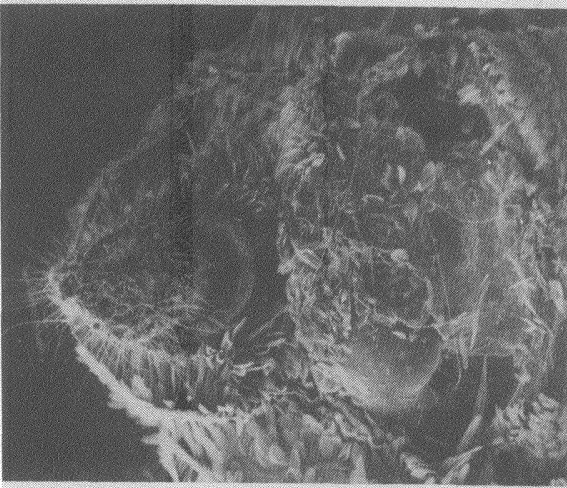

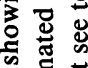

도

密

政

范

@.. \pm

蛋

훙

롫 톨

능 을

है छี

焉苋

要

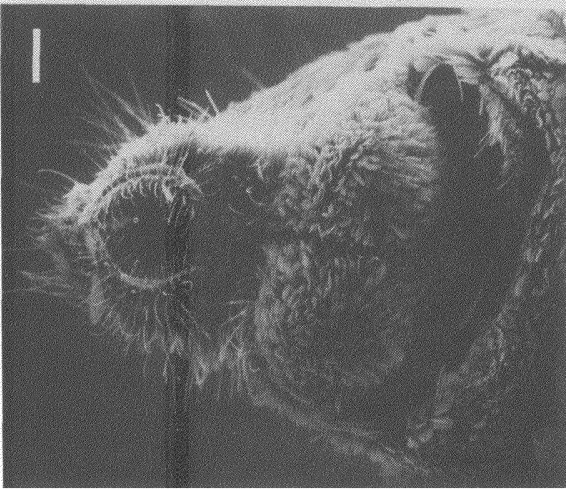

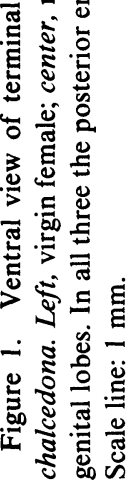


The genitalia of a mated female differ in appearance from those of a virgin (Figure 1 (center)). The scales on the large lobes are now absent and the transverse and longitudinal grooves are filled with a whitish material that is thickest in the region over the ostium bursae. This is a cohesive mass of material that is connected through the copulatory opening with the neck or collum of the spermatophore. This external extension of the collum is the mating plug or sphragis and is typically about $1 \mathrm{~mm}$ in diameter.

Figure 1 (right) shows the genitalia of a mated female whose mating plug has been removed. The ostium bursae and the transverse and longitudinal grooves are readily apparent in this micrograph.

\section{Features of the mating plug}

The mating plug varies in size among newly-mated females. In some individuals, there is no visible material outside the ostium bursae while in others the plug covers most of the lobes and fills the transverse and longitudinal grooves. In recently-mated females that have a single undeflated spermatophore in the bursa copulatrix (Rutowski and Gilchrist 1987), the size of the mating plug is positively correlated with the size of the spermatophore in the bursa copulatrix (Figure 2, $r=0.93, p>0.05$ ).

As time passes since the mating plug was formed the plug becomes somewhat brittle. Small pieces may flake off around the edge of the plug but in females caught in the field and carrying a single spermatophore there was no relationship between a female's wing wear and the area covered by the mating plug she carried. The area covered by the mating plug did not differ significantly among females that were fresh $\left(0.85 \pm 0.537 \mathrm{~mm}^{2}, \mathrm{n}=17\right.$, range $=0.188-$ $\left.2.18 \mathrm{~mm}^{2}\right)$, worn $\left(0.991 \pm 0.664 \mathrm{~mm}^{2}, \mathrm{n}=15\right.$, range $=0.0313-1.72$ $\left.\mathrm{mm}^{2}\right)$, or very worn $\left(0.832 \pm 0.584 \mathrm{~mm}^{2}, \mathrm{n}=12\right.$, range $=0.138$ $1.72 \mathrm{~mm}^{2}$; ANOVA, $\mathrm{F}=0.309,2,41 \mathrm{df}, \mathrm{p}=0.264$.)

The females mated in the field and then held in cages in the laboratory lived an average of $9 \pm 2.5$ days $(n=9$, range $6-15)$ and all had mating plugs intact at the time of death. At death, the mating plug size for these females $\left(0.511 \pm 0.352 \mathrm{~mm}^{2}\right.$, range $=0.25-1.37$ $\mathrm{mm}^{2}$ ) was not different from that for fresh females carrying a single, fresh spermatophore in the field $\left(0.85 \pm 0.537 \mathrm{~mm}^{2}, \mathrm{n}=17\right.$, range $=$ $\left.0.188-2.19 \mathrm{~mm}^{2} ; \mathrm{t}=1.7,24 \mathrm{df} ; \mathrm{p}=0.1\right)$. 


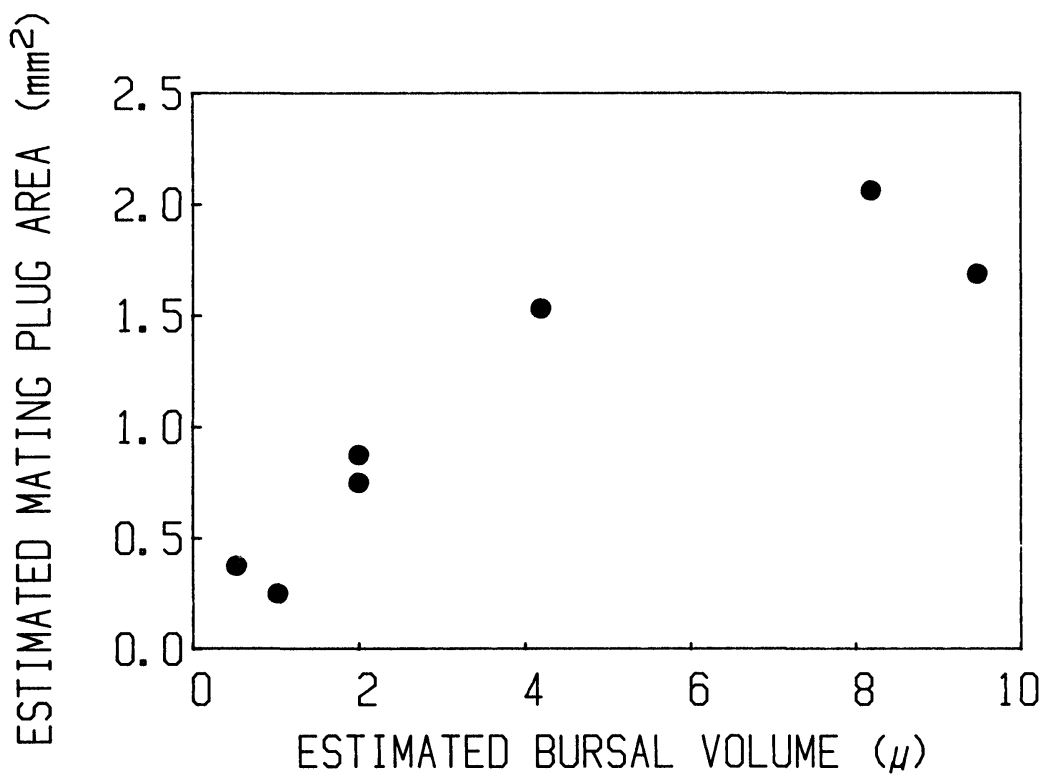

Figure 2. The relationship between the quantity of material received by a female and the external area covered by the mating plug, Data plotted are only from females that carried a single, undented seprmatophore, i.e. females that were recently mated.

Females carrying two spermatophores had mating plugs with estimated areas that were not significantly larger $(0.892 \pm 0.586$ $\mathrm{mm}^{2}$, range $=0.031-2.18 \mathrm{~mm}^{2}, \mathrm{n}=44$ ) than those for females carrying only a single spermatophore $\left(1.03 \pm 0.466 \mathrm{~mm}^{2}\right.$, range $=$ $\left.0.016-1.875 \mathrm{~mm}^{2}, \mathrm{n}=15 ; \mathrm{t}=0.82,57 \mathrm{df}, \mathrm{p}>0.05\right)$. This is in spite of the observation that females with two spermatophores carried significantly more material in their bursae $(7.52 \pm 2.52 \mu \mathrm{l}$, range $=$ $5.02-12.4 \mu \mathrm{l}, \mathrm{n}=15)$ than females that had only one spermatophore $(3.38 \pm 2.40 \mu \mathrm{l}$, range $=0.35-9.47 \mu \mathrm{l}, \mathrm{n}=44 ; \mathrm{t}=5.7,57 \mathrm{df}$, $\mathrm{p}<0.05)$.

\section{Discussion}

We draw several conclusions about the mating plug of $E$. chalcedona from these observations. First, it is clearly connected to the material deposited inside the female during copulation. Whether or not this is true of the mating plugs of other butterflies remains to be 
seen. In an evolutionary sense then the mating plug appears to be an elaboration of the secretions deposited inside the females during mating.

Second, there is considerable variation in the size of the mating plug produced by different males. Moreover, the size of the mating plug is correlated with the quantity of material placed inside the female, which indicates that the males that produce large spermatophores also produce large mating plugs. We have shown in another study (Dickinson and Rutowski, 1989) that although the mating plug mechanically impedes a male's ability to couple, males do occasionally circumvent the mating plugs carried by previously mated females. This may mean that a large plug protects a male's investment better than a small plug. However, we also observed that certain behavior patterns displayed by females are also effective deterrents to a male's copulation attempts. Hence, it is unclear if variation among males in the size of the mating plug they produce leads to variation in male reproductive success.

Third, mating plugs change somewhat in appearance and texture with time since deposition, but mating plug area does not vary with female age or number of matings. Our techniques did not examine mating plug thickness so it is possible that females that had mated more than once had mating plugs superimposed on one another. This did not appear to be the case so females do not accumulate mating plugs. A current mate either (1) removes previously deposited mating plugs at some point during mating, (2) is only successful at mating with female if she has lost the mating plugs from previous matings, or (3) circumvents the mating plug and does not deposit a new mating plug. Our data suggest that mating plugs rarely drop off. Determining which hypothesis is correct will have to await detailed observations on matings with females that have previously mated.

\section{ACKNOWLEDGMENTS}

This work was funded in part by NSF Grant No. BNS 83-00317. Assistance in the field was rendered by Ruth Stanford and Tim Lukacsko. The micrographs were taken by Charles Kazilek and printed by Barry Harmitz. For all of this help we are grateful. 


\section{REFERENCES}

Dickinson, J. L. AND R. L. Rutowski. 1989. The function of the mating plug in the chalcedon checkerspot butterfly. Anim. Behav. 38: 154-162.

Drummond, B. A. III. 1984. Multiple mating and sperm competition in the Lepidoptera. In Sperm Competition and the Evolution of Animal Mating Systems (ed. by R. L. Smith). New York, Academic Press.

Ehrlich, A. H. AND P. R. EhrLich. 1978. Reproductive strategies in the butterflies: I. Mating frequency, plugging, and egg number. J. Kansas Entomol. Soc. 51: 666-697.

LABINE, P. A. 1964. Population biology of the butterfly, Euphydryas editha. I. Barriers to multiple inseminations. Evolution 18: 335-336.

Rutowski, R. L. AND G. W. GiLChrist. 1987. Courtship, copulation and oviposition in the chalcedon checkerspot, Euphydryas chalcedona (Lepidoptera: Nymphalidae). J. Nat. Hist. 21: 1109-1117. 

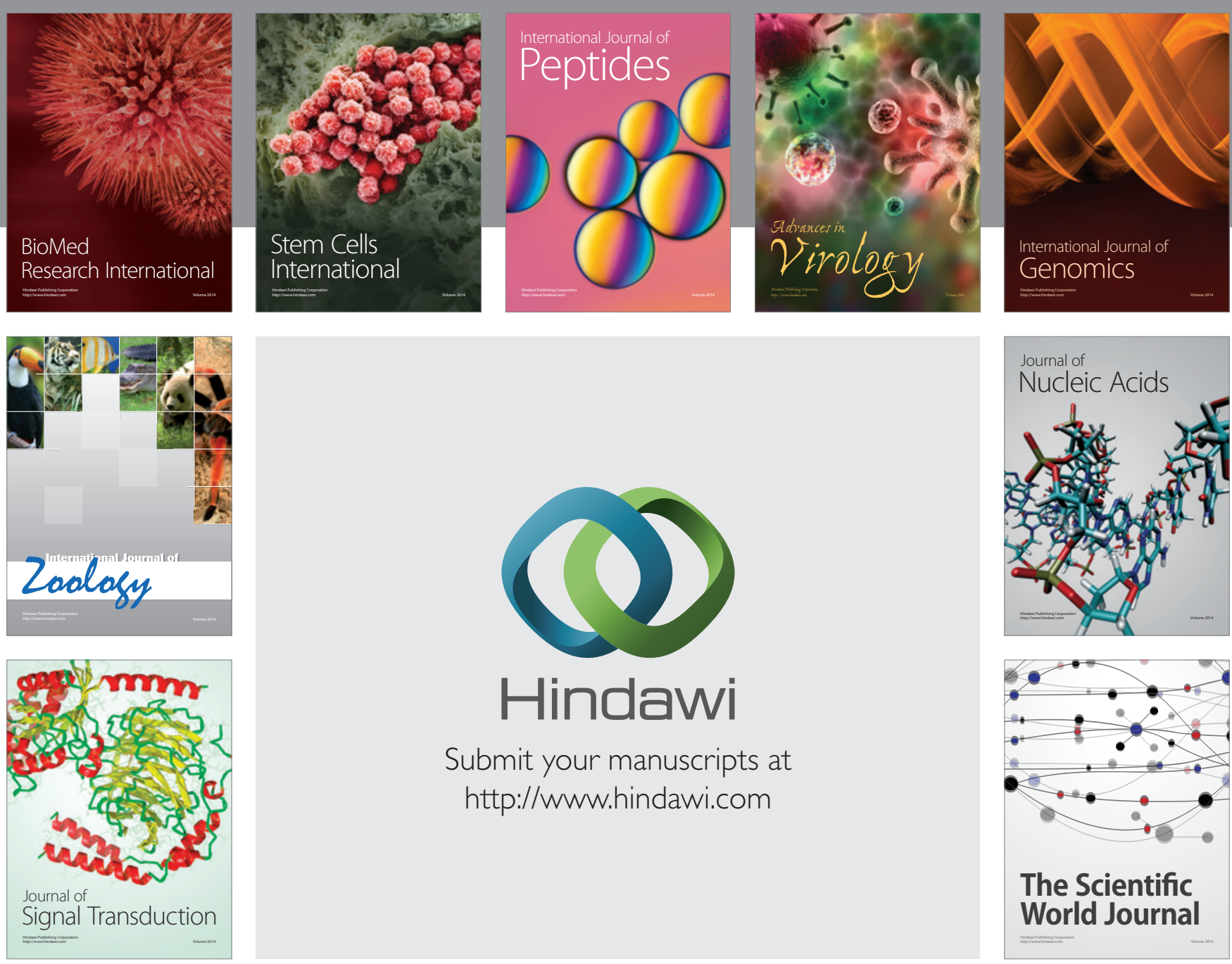

Submit your manuscripts at

http://www.hindawi.com
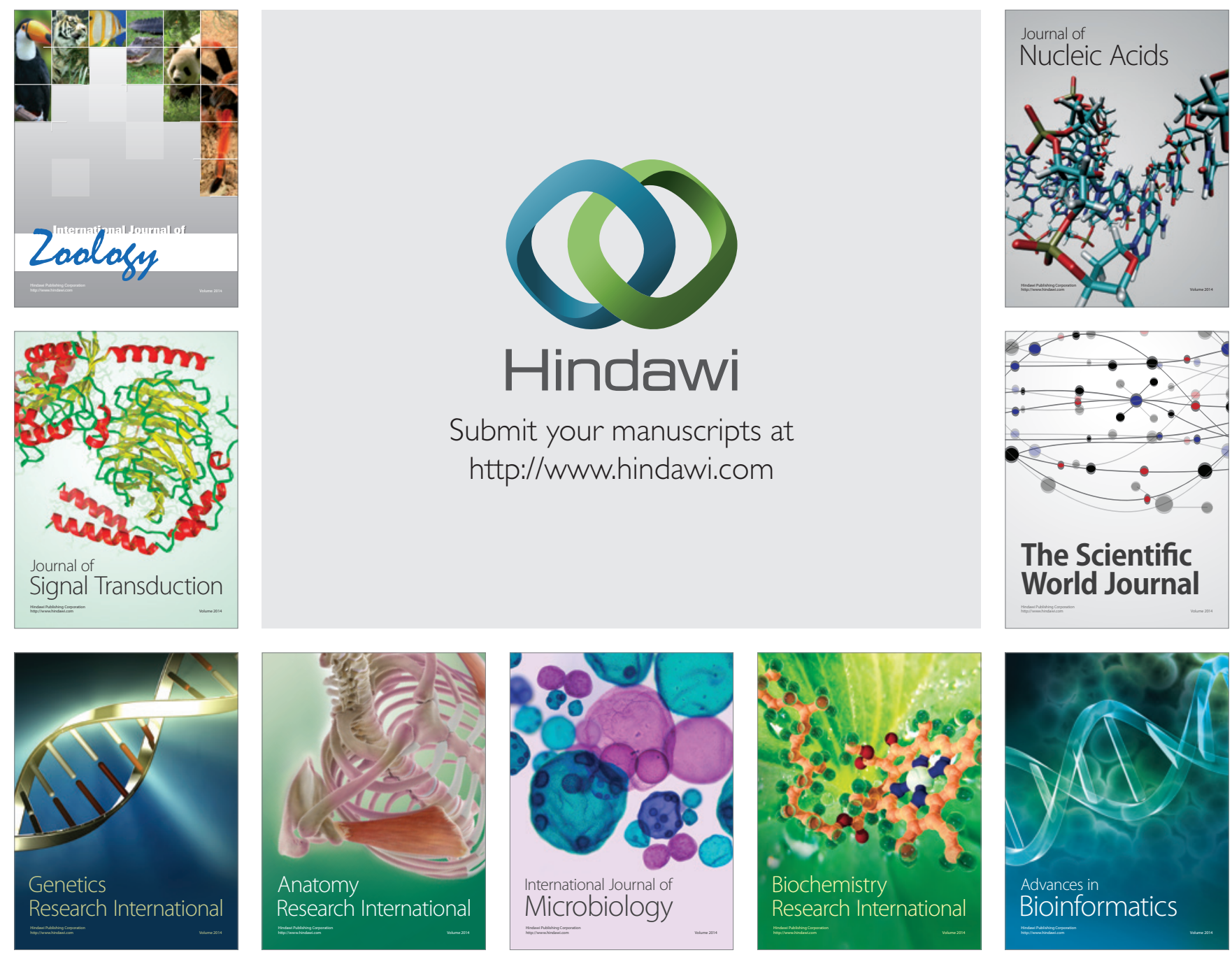

The Scientific World Journal
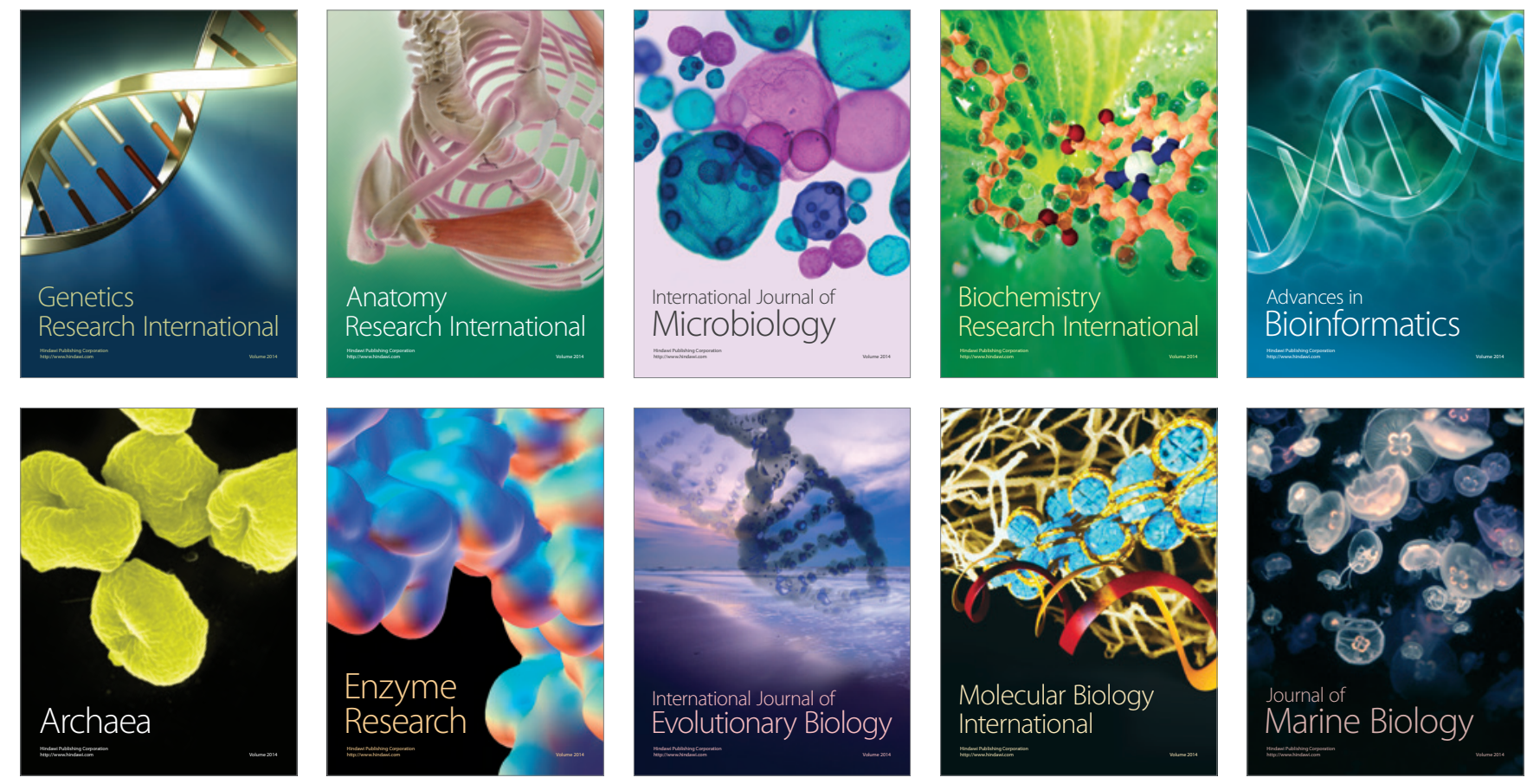